\title{
A pilot study of a rapid assessment method to identify places for AIDS prevention in Cape Town, South Africa
}

\author{
S S Weir, C Morroni, N Coetzee, J Spencer, J T Boerma
}

Sex Transm Infect 2002;78(Suppl I):i106-i 113

A multidisciplinary approach appears promising for focusing interventions. The PLACE method (priorities for local AIDS control efforts) identifies where prevention programmes can access sexual networks containing individuals with high rates of new partner acquisition and provides information about whether sexually transmitted disease (STD) or AIDS prevention programmes are in place at those sites. The method provides useful information at relatively low cost, regardless of the phase of the HIV or STD epidemic. For example, in the growth phase of an epidemic, information on where people with high rates of new partner acquisition meet new sexual partners could be used to inform targeted surveillance or screening programmes to catch early cases.

See end of article for authors' affiliations

Correspondence to Sharon S Weir, Carolina Population Center, Room 304, 123 West Franklin Street, University Square East, Chapel Hill, NC 27516-3997, USA

Accepted 30 November 2001

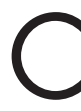
onceptual and mathematical models of epidemics of sexually transmitted infections (STI) provide the framework for improving strategies to minimise STI transmission at the population level, but improved epidemiological methods are still needed to identify, characterise, and access for intervention the key sexual networks identified in the models. The initial "core group" concept introduced by Yorke et al in 1978, ${ }^{1}$ the mathematical models ${ }^{2}$ developed by Anderson and May, and the recent phase specific model ${ }^{3}$ described by Aral and Wasserheit all highlight the importance of sexual partnership patterns among and between groups. The phase specific model argues that the optimal strategies for controlling STI require a two tiered approach for "spread" and "maintenance" networks. Mathematical models identify specific sexual network variables that influence the spread of infection including:

- behavioural heterogeneity ${ }^{4}$ - the extent to which the rate of partner acquisition and acts per partner vary within the population;

- partner concurrency ${ }^{5}$ - the extent to which partnerships overlap or are sequential;

- sexual mixing patterns-the extent to which new partner selection is random; and

- partnership timing ${ }^{6}$ - the extent to which partnerships are formed during the period of increased host infectiousness.

Unfortunately, empirical data describing sexual networks in a specific population lag behind the evolving conceptual framework. Consequently, the successful use of these features for preventing transmission of STI has been limited.

An important barrier to developing sexual network informed interventions has been the lack of rapid, reliable, and valid field methods for describing the complex and dynamic web of sexual partnering in a defined population in a way that is useful for intervention planning. By necessity, conceptual models reduce sexual behaviour and transmission networks into simple paradigms. The challenge is to translate key sexual network concepts and parameters into variables that can be measured in resource-poor settings and that provide valid indicators for phase specific intervention programming.

Traditional methods and tools for obtaining information on the sexual behavior of a population, such as general population surveys with reproductive health modules, have an individual level focus and generally do not characterise the sexual links between individuals in a population. Recent efforts to include sexual partnership modules in these surveys may prove useful in characterising the structure of sexual networks, but are not likely to provide footholds for intervention development. Full network specification theoretically would identify where to intervene most effectively, but would require an immense data collection effort that is vulnerable to significant bias. Individuals with many sexual partners may not be able to name their sexual contacts or may be unwilling to do so. ${ }^{78}$ Methods using clinic based partner notification approaches miss the majority of infected individuals who do not present for care of sexually transmitted disease (STD). They are also more likely to be informed about the stable partners of the infected case than the unreported casual sexual contacts. ${ }^{90}$ Thus there is an acknowledged gap between theoretical understanding of the types of sexual networks most capable of spreading or maintaining an epidemic and our success in measuring sexual network parameters among real individuals in a population. ${ }^{1}$

Although empiric data to describe key features of a population's sexual network can be difficult to obtain from individuals, there may be readily observable characteristics at the community level associated with its capacity to spread or sustain STD/HIV. In sub-Saharan Africa, for example, there is a recognisable pattern of geographical clustering of HIV infection by level of urbanisation. ${ }^{11}$ HIV incidence rates are generally higher in urban areas, moderate in peri-urban areas, and much lower in rural areas. ${ }^{12-16}$ In sub-Saharan Africa, areas with higher incidence of HIV infection have been dubbed "high transmission areas" (HTA). ${ }^{17}$ These are often places 
Table 1 Summary of PLACE protocol: objectives, methods, and outputs

\begin{tabular}{|c|c|c|}
\hline Objectives & Methods & Outputs \\
\hline $\begin{array}{l}\text { 1. Identify an area likely to have increased } \\
\text { incidence of HIV }\end{array}$ & $\begin{array}{l}\text { Synthesis of information from epidemiologic reports, } \\
\text { census data, health reports, maps, and discussions } \\
\text { with STD experts }\end{array}$ & $\begin{array}{l}\text { An area selected and the context of the epidemic in } \\
\text { the area described }\end{array}$ \\
\hline \multirow[t]{2}{*}{$\begin{array}{l}\text { 2. Adapt protocol, obtain community support, } \\
\text { and ethical approval. }\end{array}$} & $\begin{array}{l}\text { Consultation with community groups and ethical } \\
\text { review }\end{array}$ & \multirow{2}{*}{$\begin{array}{l}\text { Adapted approved PLACE protocol including } \\
\text { methods, sampling strategy, data collection forms, } \\
\text { interviewer manual, table shells, lists of expected } \\
\text { types of sites, and target number of key informants } \\
\text { by type }\end{array}$} \\
\hline & $\begin{array}{l}\text { Translation and back translation of } \\
\text { questionnaires/field tests of instruments }\end{array}$ & \\
\hline $\begin{array}{l}\text { 3. Identify sites and events where people meet } \\
\text { new partners }\end{array}$ & $\begin{array}{l}\text { Key informant interviews with } 300+\text { community } \\
\text { leaders, STI patients, migrants, young people, } \\
\text { beer/alcohol sellers, officials, taxi drivers, area } \\
\text { residents }\end{array}$ & $\begin{array}{l}\text { A unique list of sites where people go to meet new } \\
\text { partners as reported by key informants }\end{array}$ \\
\hline $\begin{array}{l}\text { 4. Conduct site visits to assess the validity of } \\
\text { key informant reports and characterise sites }\end{array}$ & $\begin{array}{l}\text { Site visits to all sites to verify existence and location. } \\
\text { Interview with knowledgeable person on-site }\end{array}$ & $\begin{array}{l}\text { Tables characterising the verified sites in terms } \\
\text { whether new partners are met at site, characteristics } \\
\text { of patrons, exposure to intervention, and condom } \\
\text { availability }\end{array}$ \\
\hline $\begin{array}{l}\text { 5. Estimate rate of new partner formation } \\
\text { among individuals socialising at sites. }\end{array}$ & $\begin{array}{l}\text { Brief individual interviews of sample of individuals } \\
\text { socialising at selected sites. }\end{array}$ & $\begin{array}{l}\text { Tables that describe: } \\
\text { - Rate of new and total partnerships } \\
\text { - Condom use } \\
\text { - Frequency of site attendance } \\
\text { - Sociodemographic characteristics } \\
\text { - Pattern of new partner selection }\end{array}$ \\
\hline \multirow{2}{*}{$\begin{array}{l}\text { 6. Summarise findings, estimate monitoring } \\
\text { indicators, and prepare a map useful for the } \\
\text { intervention. }\end{array}$} & Appropriate data analysis. & \multirow{2}{*}{$\begin{array}{l}\text { Report of findings including baseline indicators for } \\
\text { monitoring interventions and maps. }\end{array}$} \\
\hline & Mapping of sites on air photo or map. & \\
\hline
\end{tabular}

where social mixing intersects with commercial activity-for example: hotels for truck drivers at the intersection of major commercial routes, bars near trading centres, and migrant worker residences. ${ }^{18}$ Patrons of these places may have a higher rate of new partnership formation and be a members of a spread network. If true, then an intervention strategy for subSaharan Africa would be to focus interventions in places where social mixing occurs in the context of increased urbanisation and commercial activity.

In this paper we describe the first application of a rapid assessment method for identifying places where new sexual partnerships are formed and discuss its potential for the study of sexual networks and the focusing of interventions.

\section{METHODS}

We developed the rapid method described here and pilot tested in Cape Town, to determine whether a place focus could take advantage of the geographical clustering of STD/HIV transmission for fielding interventions to reach spread networks. The following assumptions guided our approach:

- In the absence of population based incidence data, a synthesis of available demographic and epidemiological contextual data could provide sufficient information to identify areas most likely to have partnership formation patterns capable of spreading and maintaining infection.

- Within these high transmission areas, a primary focus should be to identify places where those with highest rates of new partnership formation can be accessed because they have a disproportionate role in the epidemic.

- To minimise bias, the method should not primarily rely on self reported behaviour, contact tracing, naming of sexual partners, or require information about self reported behaviour except to validate information obtained in other ways.

- The method should be feasibly implemented in a short period of time without on-site involvement of outside technical experts.

- The method should provide programme indicators useful for intervention monitoring.

The PLACE method (priorities for local AIDS control efforts) is summarised in table 1. The first step is selection of the study area, based on a review and synthesis of available contextual and epidemiological information. In 1998, we chose Cape Town for the study because Western Cape had the lowest HIV prevalence in South Africa according to national sentinel surveillance data, but possibly the highest incidence. HIV prevalence had increased 370\% (from $1.6 \%$ to $6.3 \%$ ) among antenatal patients between 1995 and 1997. Selection of the township within Cape Town was based on the perception of a significant unmet need for STD services in the community. In addition, the township was small enough for a pilot study to be feasible.

Community approval for the study was obtained by meeting with key representatives of the principal community organisations, including political and civic organisations, health workers, the police, and community based organisations. The protocol was approved by ethics review committees at both the University of North Carolina and the University of Cape Town.

Data from the community were collected in three phases of field work. In the first phase, interviewers identified and interviewed key informants in the community. The purpose of the key informant interviews was to identify all sites in the township where residents go to meet new sexual partners. Key informants probed for all types of sites, not just sex worker "hot spots." Asking key informants to only identify sites where sex workers solicit clients would exclude most sites and require defining sex work. Key informants included people of various ages, occupations, and from different zones of the township. Interviewers scheduled appointments with community leaders, approached STD patients waiting to see a heath care provider, approached youth in the streets, asked drivers at taxi stands to point out knowledgeable taxi drivers, and approached other people at a time that seemed mutually convenient (for example, bar workers during morning hours). Interviewers requested verbal informed consent for voluntary anonymous participation. No incentives for participation were provided. Those who consented were asked to name sites where township residents meet new sexual partners. A key informant interview could be completed in 15 to 20 minutes.

The second phase of field work occurred after a unique list of sites was compiled from the hundreds of site reports obtained during the key informant interviews. Interviewers 
visited each reported site to verify its existence and location. During this visit, an interviewer asked a person knowledgeable about the site (such as a bar manager or regular patron) whether he or she believed that people come to the site to meet new sexual partners, and asked additional questions useful for planning AIDS prevention programmes at the site. These included questions about the type of site, patron characteristics, the extent of on-site AIDS prevention activities, and condom availability. The interviewer also asked for permission to return to the site and interview individuals socialising at the site. At sites reported by five or more key informants and at a sample of the remaining sites additional questions about the characteristics of the sites were asked to estimate the number of people at the site and any additional characteristics of patrons.

Verified sites were marked on an air photo of the township. The air photo was scanned into ARC-View and the site points linked to interview data. Estimates of the proportion of township residents aged 15 to 39 years visiting the sites were made from counts of people at a sample of sites, the age, sex, and residence of people interviewed at these sites, and census data from the township.

In the third phase of field work, we conducted interviews with people socialising at all sites reported by five or more key informants and a stratified random sample of sites less frequently reported. The less frequently reported sites were stratified geographically, by section of the township. The target number of respondents per selected site was 16 men and eight women. Interviewers selected respondents according to where they were standing or sitting at the site, using a method that distributed the interviews throughout the site and which could feasibly be administered by a team of two interviewers, regardless of the type of site.

Data were keyed at the University of Cape Town using EpiInfo. ${ }^{19}$ Initial analysis and data management were done using $\mathrm{SAS}^{20}$ at the University of North Carolina. We used STATA ${ }^{21}$ to adjust individual level data to take into account appropriate sampling weights. The air photo was scanned into ARC-View and the sites linked to interview data. Exploratory analysis to map mixing patterns among sites was done using ARC-View.

\section{RESULTS \\ Description of the social context of the STD/HIV epidemic \\ Population structure}

The township is located in Cape Town, South Africa, in the Western Cape Province. About 10\% of South Africa's population of 40 million live in the Western Cape province. ${ }^{22}$ It is one of two provinces in South Africa where African blacks do not constitute the majority population. The most common home language in the province is Afrikaans (spoken by $59 \%$ of the population). Over $85 \%$ of the residents of the Western Cape live in an urban area, of which the largest is Cape Town, boasting a population of more than three million. The township populations differ markedly from the rest of the residential areas in the Western Cape. According to the 1996 census, almost all residents of the study township are African black, were born in South Africa, and speak Xhosa. Females slightly outnumber males. The 80000 residents of the township live in an area smaller than $5 \mathrm{~km}^{2}$.

According to the 1996 census, over $60 \%$ of men and women aged 20 to 60 in the township have never been married and are not currently living with a partner or in a civil, religious, or traditional ceremony. ${ }^{23}$ This is much higher than the proportion of women nationally of similar age who report never having married. By age 25, fewer than $10 \%$ of the men and only $15 \%$ of the women are married; by age 35 , two thirds of both sexes remain unmarried; by age 45 over a quarter of men and a third of women remain unmarried.
Overview of the social/political economic situation

The 1996 South African census presents a picture of the township that is in sharp contrast to the more affluent population of Cape Town. Of the approximately 18000 households in the township, $41 \%$ live in informal shacks and 650 households share a one room house or shack with another household. In contrast, in the Western Cape as a whole only $7 \%$ of households live in shacks. Twice as many households in the township (47\%) live in two rooms or less compared with the rest of the province. There are 46 hostel residences that previously were designated for black workers. Since the end of apartheid, men living in these hostels have been permitted to bring their families to live with them. Instead of two single men sharing a room in a hostel, one man and his family share a room, often including members of the extended family as well as the immediate family. Twenty per cent of the households have no income. Among the population aged 15 to $60,64 \%$ are economically active-that is they are either employed or looking for work. Of the economically active population, $41 \%$ are unemployed. This is approximately twice the unemployment rate for the rest of the Western Cape.

The township is divided into approximately nine sections or zones, each with its own particular history and characteristics. These divisions of the township were used in questions about sexual mixing and in selecting sites for conducting interviews with people socialising at the sites. Boundaries of the zones are well known to residents and reflect to some extent boundaries imposed during the apartheid era. The oldest zone is the most well established, has larger houses, and, since the end of apartheid, is undergoing renovation and improvement. Two zones of the township contain buildings that previously were single sex migrant worker hostels. Several zones are experiencing uncontrolled rapid population growth in which new residences are often shacks constructed from discarded metal, wood, and cardboard.

In addition to substandard housing, cramped living conditions, and high unemployment, women living in the township may face high levels of sexual abuse. According to the 1998 Demographic and Health Survey in South Africa, among women aged 15 to 49 in the Western Cape province, $17 \%$ reported having ever been abused by a sexual partner; $8 \%$ reported that the abuse occurred within the past year; and $6.5 \%$ reported ever being raped. ${ }^{24}$ Although this survey probably underestimates the extent of rape, the Western Cape had the second highest level of rape reported for a province. We do not know if sexual abuse is higher in the townships than in other parts of the province.

\section{Public health infrastructure and STD services}

There are six public health clinics in the township, one hospital, and very few private practitioners. The policy for treating patients who present with STD complaints is syndromic treatment according to the standard national guidelines. New cases of STDs can be seen in any of the clinics or the hospital, but individuals are only provided follow up care in the clinic closest to their residence. STD service providers indicated that there is inadequate access to appropriate STD care in the township.

\section{Place based description of sexual networks: where people meet new sexual partners Identification of sites}

We characterised sexual networks according to the type and location of sites reported by key informants where new partnerships are formed, mixing between the sites, and the rates of partner formation at the sites. In all, 318 key informants were interviewed over a 10 day period by a team of seven field workers. About two thirds of the key informants were adolescents, taxi drivers, and patients at the STD clinic. The others included the police, public officials, nurses, and business owners. Forty per cent of the key informants were female. Almost 
all had completed grade 7 . Over half had lived in the township all their life; another $10 \%$ had lived in the township more than 10 years. Only 12\% were not residents of the township. Field workers could not locate any self identified sex workers to interview. Only two key informants did not report any site; the mean number of sites reported per key informant was 2.7.

\section{Characteristics of sites and mapping}

The second phase of field work required eight days of intensive field work during which 12 field staff tried to locate the 363 sites reported by the key informants. Of the 363 sites, 310 sites $(85 \%)$ were located, the address verified or corrected if necessary, the site characterised, and a responsible person on-site such as a bar manager interviewed. Sites were distributed throughout the township, although there was some clustering of sites in the north and south (fig 1) near former migrant worker hostels.

Almost all of the sites served beer or alcohol. Over three quarters of the sites were shebeens (table 2). A shebeen is typically a four room house in a residential area that has been converted to accommodate beer and alcohol sales and consumption. About $14 \%$ of the sites were taverns. Taverns are more likely to be legally registered to sell beer and alcohol and can serve a larger crowd. Besides shebeens and taverns, key informants reported a community hall, a church, a nightclub, a takeaway food stand, a garage, a shack, and a hair salon. None of the key informants reported a brothel or anywhere characterised by the presence of commercial sex. Field staff could not find any brothels or escort services in the township. Twenty eight sites were reported by five or more key informants. Almost half of these were taverns even though taverns represented only about $15 \%$ of the total number of sites reported.

About three quarters of the knowledgeable people interviewed about the characteristics of the site reported that people come to the site to meet new sexual partners. About $40 \%$ reported that patrons are exclusively from the zone in the township where the site is located. The remainder reported that people come from more than one zone in the township and often from throughout the township. About $12 \%$ reported that some patrons are from outside the township. When asked to describe those who visit in terms of age and sex, the most commonly reported groups were men aged 25 to 30 and women aged 16 to 24 . More than $40 \%$ of those interviewed reported that adolescents younger than 16 visit the site. Over $10 \%$ reported that girls younger than 16 visit the site. When managers at a subset of 49 sites were asked in an open ended question to characterise patrons, the most common response was "Everybody." Almost half spontaneously responded either "students" or "youth."

Fewer than $2 \%$ of the 310 sites had any on-site AIDS prevention activities such as educational materials, peer education programmes, or visits by health outreach workers. Over $90 \%$ never had condoms available on-site. Condoms were reportedly available "nearby" at $22 \%$ of sites, although in most cases this referred to condoms available at a health facility. Almost $60 \%$ of the people interviewed about the characteristics of the site and its patrons reported that they would be willing to sell condoms at the site.

\section{Characteristics of people socialising at sites}

In the third phase of field work, 738 men and 378 women were interviewed at 26 of the 28 sites reported by five or more key informants, and at a stratified random sample $(n=23)$ of the remaining sites. (Where the target number of 24 interviews was not reached in a site, it was usually because there were fewer than 16 men and eight women on site at the time of the interview.) No important differences in behaviour emerged among those interviewed at frequently reported $v$ less frequently reported sites. Thus we merged the data using the

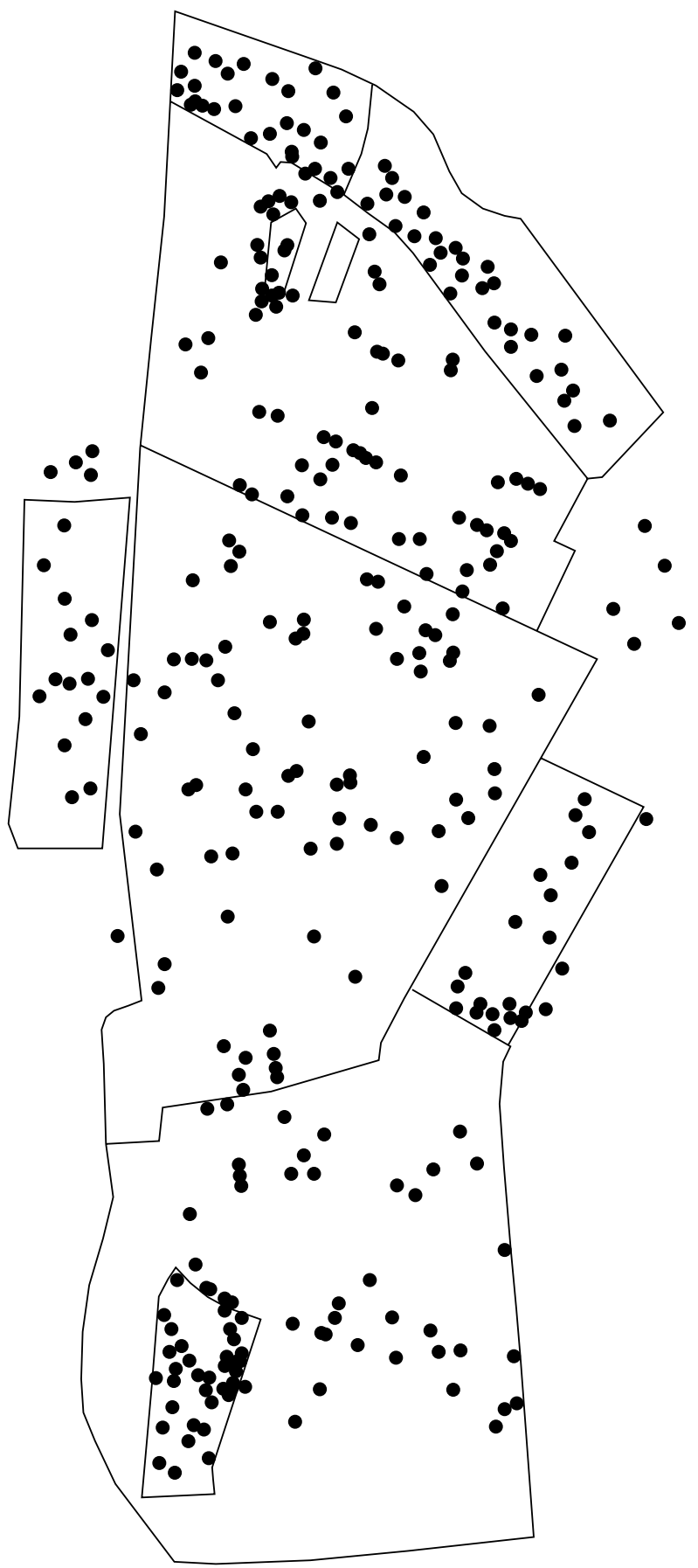

Figure 1 Sites where people meet new sexual partners in the township.

appropriate sampling weights. Interviews were conducted during late afternoons and evenings.

The mean age of men and women was approximately 30 years, although a greater proportion of women was younger than 25 (table 3 ). Over $85 \%$ of respondents were residents of the township (table 3), although women were more likely than men to be from outside the township. Over half had lived all their life in the township. About a third of the respondents had not completed Standard 8 level of schooling, but there were not marked differences in educational attainment by sex. About $40 \%$ of the respondents were unemployed. Very few people reported that the evening of the interview was their first time to visit the site (table 4). Over a quarter of those interviewed reported visiting the site more than 10 times a 
Table 2 Characteristics of sites obtained from manager or knowledgeable person at site

\begin{tabular}{|c|c|c|c|}
\hline Number of sites & 310 & & \\
\hline \multirow{4}{*}{$\begin{array}{l}\text { Per cent reporting that people meet new sexual partners at } \\
\text { the site }\end{array}$} & 73.9 & Number of people counted at the site & ( $n=46$ sites) \\
\hline & & Men: & \\
\hline & & Mean & 46 \\
\hline & & Median & 30 \\
\hline \multicolumn{4}{|l|}{ Type of site } \\
\hline Tavern & 14.5 & & ( $n=43$ sites) \\
\hline Shebeen & 78.1 & Women & \\
\hline Hostel & 2.9 & Mean & 23 \\
\hline Church & 0.6 & Median & 15 \\
\hline Community hall & 0.6 & & \\
\hline Night club & 0.6 & On site activities ( $\%$ answering yes) & ( $n=49$ sites) \\
\hline Take-away & 1.6 & Men "fish" on site for sexual partners? & 79.6 \\
\hline Garage & 0.3 & Women "fish" on site for sexual partners? & 79.6 \\
\hline Shack & 0.3 & Facilitator available for finding partner? & 34.7 \\
\hline Salon & 0.3 & Beer consumed? & 91.8 \\
\hline \multirow[t]{2}{*}{ Total } & 100.0 & Alcohol consumed? & 91.8 \\
\hline & & TV or video on site? & 51.0 \\
\hline \multicolumn{2}{|l|}{ AIDS activities on site (\% with) } & Sex workers solicit on site? & 4.1 \\
\hline Any educational materials & 1.3 & Sex occurs on site? & 4.1 \\
\hline Any AIDS prevention activities & 1.6 & & \\
\hline Any AIDS talks & 1.0 & Characteristics spontaneously mentioned when asked to & ( $n=49$ sites) \\
\hline Any peer education & 0.0 & describe patrons of site & \\
\hline \multirow[t]{2}{*}{ Any health outreach worker visits } & 0.3 & Everybody & 38.8 \\
\hline & & Students & 24.5 \\
\hline Condom availability (\% Yes) & & Youth & 18.4 \\
\hline Any condoms on-site at time of visit & 2.9 & Non-residents of township & 18.4 \\
\hline Any condoms nearby & 22.3 & Residents of township & 14.3 \\
\hline Condoms always available here & 0.6 & Business men & 13.0 \\
\hline Condom sometimes available here & 6.1 & Professional people & 10.2 \\
\hline Condoms never available here & 92.2 & Unemployed & 10.2 \\
\hline \multirow[t]{2}{*}{ Respondent willing to sell condoms at site } & 58.7 & Older people & 6.1 \\
\hline & & Men only & 6.1 \\
\hline Sexual mixing & & People of all ages & 6.1 \\
\hline Where do people come from who come to this site? & & Migrant workers & 4.1 \\
\hline From outside township and & & People with low education & 2.9 \\
\hline From all over township & 4.2 & & \\
\hline From 3-4 zones in township & 1.6 & & \\
\hline From 0-2 zones in township & 5.5 & & \\
\hline \multicolumn{4}{|l|}{ Not from outside township but: } \\
\hline From all over township & 17.7 & & \\
\hline From 3-4 zones in township & 16.1 & & \\
\hline From 2 zones in township & 14.2 & & \\
\hline From 1 zone in township & 40.3 & & \\
\hline No specific areas mentioned & 0.3 & & \\
\hline Total & 100.0 & & \\
\hline
\end{tabular}

Table 3 Characteristics of men and women socialising at sites

\begin{tabular}{|c|c|c|c|c|c|}
\hline & $\begin{array}{l}\text { Men } \\
(n=738)\end{array}$ & $\begin{array}{l}\text { Women } \\
(n=378)\end{array}$ & & $\begin{array}{l}\text { Men } \\
(n=738)\end{array}$ & $\begin{array}{l}\text { Women } \\
(n=378)\end{array}$ \\
\hline Age (years) & & & Time residing in township & & \\
\hline $15-19$ & 2.8 & 3.8 & $<1$ year & 2.4 & 4.4 \\
\hline $20-24$ & 17.1 & 23.7 & 1 year & 1.6 & 1.1 \\
\hline $25-29$ & 32.2 & 31.7 & $2-4$ years & 8.9 & 5.7 \\
\hline $30-34$ & 24.0 & 22.9 & $5-10$ years & 13.5 & 8.1 \\
\hline $35-39$ & 15.4 & 10.2 & $>10$ years & 11.7 & 11.0 \\
\hline$\geqslant 40$ & 8.4 & 7.7 & All life & 53.5 & 51.2 \\
\hline Total & 100.0 & 100.0 & Does not reside in township & 8.4 & 18.5 \\
\hline Mean age & 30.1 & 29.1 & Total & 100.0 & 100.0 \\
\hline Current residence & & & Educational attainment & & \\
\hline Township & 91.6 & 81.8 & None & 0.0 & 0.6 \\
\hline Elsewhere in Cape Town & 8.0 & 17.2 & $<$ Standard 5 & 5.8 & 4.9 \\
\hline Elsewhere in South Africa & 0.3 & 0.5 & Standard 6-8 & 26.0 & 28.9 \\
\hline Outside South Africa & 0.0 & 0.5 & Standard 9-10 & 49.8 & 49.8 \\
\hline \multirow[t]{2}{*}{ Total } & 100.0 & 100.0 & Tertiary & 18.0 & 15.7 \\
\hline & & & Total & 100.0 & 100.0 \\
\hline \multicolumn{6}{|l|}{ Employment status } \\
\hline Employed & 55.0 & 61.0 & & & \\
\hline Not employed & 45.0 & 39.0 & & & \\
\hline Total & 100.0 & 100.0 & & & \\
\hline
\end{tabular}


Table 4 Sexual partnerships at sites according to individuals socialising at sites

\begin{tabular}{|c|c|c|}
\hline & Men $(n=738)$ & Women $(n=378)$ \\
\hline \multicolumn{3}{|c|}{ Do you believe people come here to meet new partners? } \\
\hline Yes & 80.4 & 81.6 \\
\hline No & 19.7 & 18.5 \\
\hline Total & 100.0 & 100.0 \\
\hline \multicolumn{3}{|c|}{ Have you ever attracted a partner at this site? } \\
\hline Yes & 41.0 & 29.4 \\
\hline No & 59.0 & 70.6 \\
\hline Total & 100.0 & 100.0 \\
\hline \multicolumn{3}{|c|}{ Frequency of attendance at site } \\
\hline First time & 3.5 & 8.2 \\
\hline$<1$ time a month & 7.2 & 11.8 \\
\hline $1-2$ times a month & 17.8 & 21.8 \\
\hline $3-5$ times a month & 21.6 & 18.8 \\
\hline $6-10$ times a month & 18.4 & 14.7 \\
\hline$>10$ times a month & 31.6 & 24.7 \\
\hline Total & 100.0 & 100.0 \\
\hline \multicolumn{3}{|c|}{ When did you last attract a partner at this site? } \\
\hline Past month & 11.8 & 8.9 \\
\hline $2-3$ months ago & 11.5 & 10.0 \\
\hline $4-6$ months ago & 6.8 & 4.6 \\
\hline $7-12$ months ago & 9.6 & 1.8 \\
\hline Over a year ago & 1.4 & 3.5 \\
\hline Never & 58.8 & 71.2 \\
\hline Total & 100.0 & 100.0 \\
\hline \multicolumn{3}{|l|}{ Ever used a condom? } \\
\hline Yes & 51.7 & 59.2 \\
\hline No & 48.4 & 40.9 \\
\hline Total & 100.0 & 100.0 \\
\hline \multicolumn{3}{|c|}{ Condom used most recent sex? } \\
\hline Yes & 29.2 & 35.9 \\
\hline No & 23.5 & 25.8 \\
\hline Never used a condom & 47.3 & 38.4 \\
\hline Total & 100.0 & 100.0 \\
\hline \multicolumn{3}{|c|}{ Condom use with your most recent partner from here? } \\
\hline Yes & 19.7 & 16.8 \\
\hline No & 36.7 & 27.5 \\
\hline No partner from here & 43.7 & 55.6 \\
\hline Total & 100.0 & 100.0 \\
\hline \multicolumn{3}{|c|}{ Any most recent 3 partners attracted at site } \\
\hline Yes & 37.5 & 29.6 \\
\hline No & 62.5 & 70.4 \\
\hline Total & 100.0 & 100.0 \\
\hline \multicolumn{3}{|c|}{ Whether goes to any area in township to meet new partners } \\
\hline Yes & 57.0 & 50.4 \\
\hline No & 43.0 & 49.6 \\
\hline Total & 100.0 & 100.0 \\
\hline \multicolumn{3}{|c|}{ Whether goes outside the township to meet new partners } \\
\hline Yes & 60.3 & 53.8 \\
\hline No & 39.7 & 46.2 \\
\hline Total & 100.0 & 100.0 \\
\hline \multicolumn{3}{|c|}{ Whether goes in and outside the township to meet new partners } \\
\hline Yes & 37.1 & 30.1 \\
\hline No & 62.9 & 69.9 \\
\hline Total & 100.0 & 100.0 \\
\hline
\end{tabular}

month. More than half of those interviewed visited the site more than three times a month.

When asked if people come to the site to meet new sexual partners, over $80 \%$ of men and women replied affirmatively (table 4). About $40 \%$ of the men and $30 \%$ of the women reported personally having met a new partner at the site, and about half of these reported that they had met a new partner at the site within the past three months. Even though fewer than half of the respondents reported meeting a partner at the site of the interview, half reported going somewhere in the township to meet new sexual partners. Sixty per cent of the men and $54 \%$ of the women reported going outside the township to meet new sexual partners.
Between $40 \%$ and $50 \%$ of all respondents had never used a condom, and less than one third reported using a condom at the most recent coitus. Self reported condom use did not vary significantly by sex or by whether the site of the interview was identified by five or more key informants.

Respondents were asked how many different sexual partners they had had in the past four weeks and in the past year, and how many of these partners were new in the past four weeks and in the past year (table 5). These self reported rates were higher for men than for women. Men reported a mean of 2.3 different partners and 1.2 new partners in the past four weeks. Women reported a mean of 1.8 total partners and 0.9 new partners in the past four weeks. About $20 \%$ of the men reported four or more partners in the past four weeks; a third reported two or more new partners in the past four weeks. About half of men reported having more than one partner in the past four weeks, and among these men, almost all reported that at least one of these partners was new. Over $40 \%$ of women reported having more than one sexual partner in the past four weeks and of these, almost all reported a new partnership in the past four weeks.

Key indicators useful for AIDS prevention programmes identified from these data include:

- the number of sites identified in the township where people meet new sexual partners-363 sites, of which 313 were verified;

- the percent of verified sites with condoms available-3\%;

- the mean rate of new partnership formation at sites in the past four weeks, by sex-1.2 for men and 0.9 for women;

- the proportion of those socialising at sites who have ever used a condom, by sex- $52 \%$ for men and $59 \%$ for women;

- the proportion of those socialising at sites using condoms at most recent coitus-29\% for men and 36\% for women; and

- the proportion of those socialising at sites using condoms with the most recent sexual partner from the site- $35 \%$ of men and $38 \%$ of women.

\section{DISCUSSION}

This rapid assessment suggests that in this Western Cape township, spread networks important for transmitting HIV and other sexually transmitted infections can be accessed for prevention programmes at bars and shebeens. Although we do not have biomedical evidence that the incidence of HIV infection is any higher in the township than elsewhere, this study suggests that the sexual network in the township could easily spread HIV and other sexually transmitted infections. The rates of new partner acquisition in the past four weeks reported from individuals socialising at the sites are more than double the rate of partner change estimated necessary to sustain transmission of HIV, gonorrhoea, chlamydia, or syphilis. ${ }^{25}$ In addition, these reported rates of partner acquisition are much higher than those reported nationally in South Africa. ${ }^{26}$ In our study women reported a mean of 1.8 total partners and 0.9 new partners in the past four weeks; in the national survey women aged 15 to 49 reported a mean of 0.8 total partners in the past 12 months. Finally, key factors that might mitigate the epidemic are missing. Treatment of other sexually transmitted disease is inadequate. Condom use is low and they are not available.

The assessment suggests that place based assessments may be able to circumvent the need for full sexual network specification and identify areas for intervention (such as the township) and specific sites within the area (such as the bars and shebeens with the highest rates of new partner acquisition). Where population based data are not available, it is more efficient to use available sociodemographic and epidemiological data to identify areas likely to have spread networks than construct a community's sexual network from 
Table 5 Rates of partnership formation

\begin{tabular}{|c|c|c|c|c|c|}
\hline & Men $(n=738)$ & Women $(n=378)$ & & Men $(n=738)$ & Women $(n=378)$ \\
\hline \multicolumn{3}{|c|}{ Number of partners in past 4 weeks } & \multicolumn{3}{|c|}{ Number of new partners in past 4 weeks } \\
\hline 0 & 1.4 & 2.3 & 0 & 36.2 & 38.4 \\
\hline 1 & 45.6 & 55.4 & 1 & 32.2 & 44.8 \\
\hline 2 & 18.0 & 21.7 & 2 & 17.2 & 12.8 \\
\hline 3 & 15.7 & 14.3 & 3 & 9.2 & 2.3 \\
\hline $4-9$ & 18.2 & 5.7 & 4-9 & 5.2 & 1.7 \\
\hline $10-14$ & 0.9 & 0.6 & Total & 100.0 & 100.0 \\
\hline$>15$ & 0.3 & 0.0 & & & \\
\hline Total & 100.0 & 100.0 & & & \\
\hline Mean & 2.3 & 1.8 & Mean & 1.2 & 0.9 \\
\hline Median & 2 & 1 & Median & 1 & 1 \\
\hline Range & $0-16$ & $0-12$ & Range & $0-9$ & $0-7$ \\
\hline \multicolumn{3}{|c|}{ Number of partners in past year } & \multicolumn{3}{|c|}{ Number of new partners in past year } \\
\hline 0 & 0.6 & 2.7 & 0 & 12.0 & 19.9 \\
\hline 1 & 23.1 & 37.9 & 1 & 25.1 & 37.4 \\
\hline 2 & 10.7 & 15.0 & 2 & 22.9 & 19.4 \\
\hline 3 & 20.2 & 15.5 & 3 & 12.6 & 10.1 \\
\hline $4-9$ & 31.8 & 22.0 & $4-9$ & 23.9 & 12.1 \\
\hline $10-14$ & 8.9 & 3.6 & $10-14$ & 3.0 & 1.1 \\
\hline$>15$ & 4.6 & 3.2 & $>15$ & 0.5 & 0.0 \\
\hline Total & 100.0 & 100.0 & Total & 100.0 & 100.0 \\
\hline Mean & 5.0 & 3.5 & Mean & 2.8 & 1.9 \\
\hline Median & 3 & 2 & Median & 2 & 1 \\
\hline
\end{tabular}

individual self reports or from large and expensive household surveys. We identified the township based on available epidemiological and sociodemographic data and the opinion of experienced health care service providers in the community. More research could be done to identify community level factors associated with increased transmission of sexually transmitted infections. Especially in sub-Saharan Africa, where core group membership is not easy to define or measure in a population and epidemics may be geographically clustered, ${ }^{27}$ targeting areas for intervention could be a reasonable prevention strategy.

In addition to identifying footholds for intervention, a place based approach is compatible with a population perspective that focuses on preventing transmission at the population level rather than acquisition at the individual level. ${ }^{28}$ In sub-Saharan Africa, however, where high proportions of the sexually active population are already infected with HIV, targeting "core groups" has proven difficult to translate into an effective prevention strategy. The PLACE method is an alternative strategy for identifying core groups. Rather than identifying core groups based on occupation (for example, sex workers, the military, truck drivers), the focus shifts to identifying spread networks through the places (areas and sites within these areas) where new partner acquisition occurs. Spread networks clearly include individuals with high rates of new partnership acquisition, regardless of their occupation.

Identifying where people in the community go to meet new sexual partners rather than asking about groups which may carry some stigma (for example, commercial sex workers, drug abusers, gay and bisexual populations) may be less stigmatising and more likely to uncover spread networks. Prevention efforts targeting sex workers (male or female), transport workers, the military, or drug abusing populations would have missed the township entirely. We found that key informants did not object to identifying where people go to meet new sexual partners, whereas they denied that commercial sex existed in the township. However, we focused primarily on asking where people go to meet new sexual partners because within a sexual network new sexual partnerships hold a strategic position in the epidemiology of HIV/STD transmission. Preventing a case of HIV infection among the subpopulation with high rates of new partner acquisition may reduce the number of individuals exposed to HIV during the period of primary infection.

The frequency of attendance at the sites was much higher than expected. About one third of respondents reported visiting the site more than 10 times a month, suggesting that visiting shebeens and taverns is part of the daily lifestyle for some community members. We used census data and data from the study to roughly estimate that 6000 men and 2400 women visit the sites. This represents about $30 \%$ of male and $10 \%$ of female township residents age 15 to 39. Additional work should be done to improve methods for estimating the proportion of residents in the township who visit places where people meet new sexual partners.

This was the first application of the method in a community. Since October 1999 when the study was conducted in Cape Town, we have adapted and improved the protocol for implementation in other settings in South Africa, Tanzania, Uganda, Burkina Faso, Mexico, and Russia. Several areas for improvement of the protocol have emerged. We need better information about site dynamics, including changes in the characteristics of patrons of the sites, site closings, and mixing among sites. Although we tried to locate every site in the township where people meet new partners, we undoubtedly missed some sites. Further research must be done to quantify the extent to which sites are missed. Undoubtedly there are high transmission "times" as well as high transmission areas. We interviewed people at the end of the month during a 10 day period that included two weekends, the usual monthly payday, and a holiday. We do not know to what extent the population fluctuates during the month. People were not reluctant to answer questions about how many sexual partners they had, but we do not know the extent or direction of bias in their responses.

We did not link this assessment with the development of an intervention in Cape Town. In three other sites in South Africa, however, the assessments are being linked from the outset with place based interventions. The components of the intervention include peer health education at key sites, condom promotion at sites, and recruitment of vulnerable women identified at sites to "fast lanes" for STD screening and treatment. For these interventions, indicators for programme 
inputs, outputs, and outcomes at the site level and at the area level are being developed.

\section{Conclusions}

This multidisciplinary approach appears promising for focusing interventions. The PLACE method identifies where prevention programmes can access sexual networks containing individuals with high rates of new partner acquisition and provides information about whether STD or AIDS prevention programmes are in place at those sites. The method provides useful information at relatively low cost regardless of the phase of the HIV or STI epidemic. For example, in the growth phase of an epidemic, information on where people with high rates of new partner acquisition meet new sexual partners could be used to inform targeted surveillance or screening programmes to catch early cases. In the hyperendemic phase, the information could be used in targeted community outreach programmes. As the epidemic declines, the information could be used to monitor whether intervention programmes are continuing to reach sites with spread networks and whether new sites or networks have arisen. Regardless of the phase of the epidemic, knowledge of the underlying patterns of risk behavior is clearly valuable in determining where to distribute prevention resources.

Finally, we recognise the need for additional research to improve the method and optimise its usefulness in preventing transmission of STI. For example, research to validate whether the incidence of STI in areas identified with this method is in fact higher than in other areas. We also need research to assess which indicators should be used to prioritise sites for prevention programmes. For example, should the focus be on sites with the highest new partnership rates? Or on sites with the most mixing between township residents and non-residents? Or on the sites most frequently reported? Or on sites that are the most popular with the youth? Or on sites that are the most receptive to educational interventions and condom promotion? The phase of the epidemic would clearly affect which indicators are most useful for focusing prevention programmes. Answering these questions will increase the usefulness of this approach to people responsible for implementing local STI prevention programmes.

\section{ACKNOWLEDGEMENT}

We wish to thank Ms Regina Dlakulu for her tireless efforts to identify and map sites, Ron Roddy for his early involvement in the study, and Dr Sevgi Aral, Dr Jamie Blanchard, and Dr Bernard Schwartlander for their thoughtful reviews.

\section{Authors' affiliations}

S S Weir, Carolina Population Center, University of North Carolina, Chapel Hill, North Carolina, USA

C Morroni, Medical Research Council, Cape Town, South Africa

N Coetzee, University of Cape Town, Cape Town

J Spencer, Carolina Population Center, University of North Carolina

J T Boerma, Carolina Population Center, University of North Carolina

\section{REFERENCES}

1 Yorke JA, Hethcote HW, Nold A. Dynamics and control of the transmission of gonorrhea. Sex Transm Dis 1978;5:51-7.
2 Garnett GP, Anderson RM. Sexually transmitted diseases and sexual behavior: insights from mathematical models. J Infect Dis 1996:174(suppl 2):s150-61

3 Wasserheit JN, Aral SO. The dynamic topology of sexually transmitted disease epidemics: implications for prevention strategies. J Infect Dis 1996; 174(suppl 2):S201-13.

4 Anderson R. Transmission dynamics of sexually transmitted infections. In: Holmes KK, Sparling PF, Mardh P-A, et al, eds. Sexually transmitted diseases, 3rd ed. New York: McGraw Hill, 1999:25-37.

5 Morris $M$, Kretzschmar M. Concurrent partnerships and the spread of HIV. AIDS 1997;11:641-8.

6 Koopman JS, Jaquex JA, Welch GW, et al. The role of early HIV infection in the spread of HIV through populations. J Acquir Immune Defic Syndr Hum Retrovirol 1997; 14:249-58.

7 Woodhouse DE, Rothenberg RB, Potterat JJ, et al. Mapping a social network of heterosexuals at high risk for HIV infection. AIDS 1994:8:1331-6.

8 Ghani AC, Donnelly CA, Garnett GP. Sampling biases and missing data in explorations of sexual partner networks for the spread of sexually transmitted diseases. Stat Med 1998;17:2079-97.

9 Coeetzee N, Matthews C, McCoy D. Partner notification in the management of sexually transmitted diseases-options for South Africa. $S$ Afr Med J 1996;86: 1478-9.

10 Coetzee N, Visser H, Mofokeng M, et al. Misses opportunities for partner notification in sexually transmitted disease clinics in Cape Town. South Afr J Epidemiol Infect 1996;1 1:44-7.

11 Boerma JT, Urassa M, Klokke AH, et al. Spread of HIV in a rural area in Tanzania. AIDS 1999;13:1233-40.

12 Carael M. Urban-rural differentials in HIV/STDs and sexual behaviour. In: Herdt G, ed. Sexual cultures and migration in the era of AIDS: anthropological and demographic perspectives. Oxford: Oxford University Press, 1997: 107-26.

13 Barongo LR, Borgdorff MW, Mosha F, et al. The epidemiology of HIV-1 infection in urban areas, roadside settlements and rural villages in Mwanza Regon, Tanzania. AIDS 1992;6:1521-8.

14 Wawer M, Serwadda D, Musgrave SD, et al. Dynamics of the spread of HIV-1 infection in a rural district of Uganda. BM 1991;303:1301-6.

15 Anderson RM, May RM, Boily MC, et al. The spread of HIV 1 in Africa: sexual contact patterns and the predicted demographic impact of AIDS. Nature 1991;352:581-9.

16 Kipp W, Kabwa P, Verback A, et al. Prevalence and risk factors of HIV-1 infection in three parishes in western Uganda. Trop Med Parasitol 1995;46:141-6.

17 Mwizarubi B, Hamelmann, Nyamuryekung'e K. Working in high transmission areas: truck routes. In: $\mathrm{Ng}^{\prime}$ weshemi JZL et al, eds. HIV prevention and AIDS care in Africa: a district level approach. Amsterdam: Royal Tropical Institute Press, 1997:137-49.

18 Boerma T, Urassa M. Situation analysis for a district HIV/AIDS programme. In: HIV prevention and care in Africa: a district level approach. Amsterdam: Royal Tropical Institute, 1997:39-50.

19 Epi-Info, Version 6. Division of Surveillance and Epidemiology, Epidemiology Program Office, Centers for Disease Control, Atlanta, Georgia 30333, USA.

20 SAS Version 7, SAS Institute, Cary, North Carolina, USA.

21 StataCorp. Stata Statistical Software: release 6.0. College Station, Texas: Stata Corporation, 1999.

22 Statistics South Africa. The people of South Africa population census: census in brief. Report No: 03-01-11, 1996.

23 Census data for the township obtained from the Western Cape Provincial office of Statistics, South Africa. Data gathered in October 1996.

24 South Africa Demographic and Health Survey, 1998. Preliminary report, p 23.

25 Brunham RC, Plummer FA. A general model of sexually transmitted disease epidemiology and its implications for control. Med Clin North Am 1990;74:1339-52.

26 South Africa Demographic and Health Survey, 1998. Preliminary report, $\mathrm{p} 15$.

27 Boerma JT, Urassa M, Nnko S, et al. Sociodemographic context of the AIDS epidemic in a rural area with a focus on people's mobility and marriage. Sex Transm Infect 2002;78(suppl I): i97-105.

28 Aral SO, Holmes KK, Padian NS, et al. Overview: individual and population approaches to the epidemiology and prevention of sexually transmitted diseases and human immunodeficiency virus infection. Sex Transm Dis 1996;154(suppl 2):S127-33. 